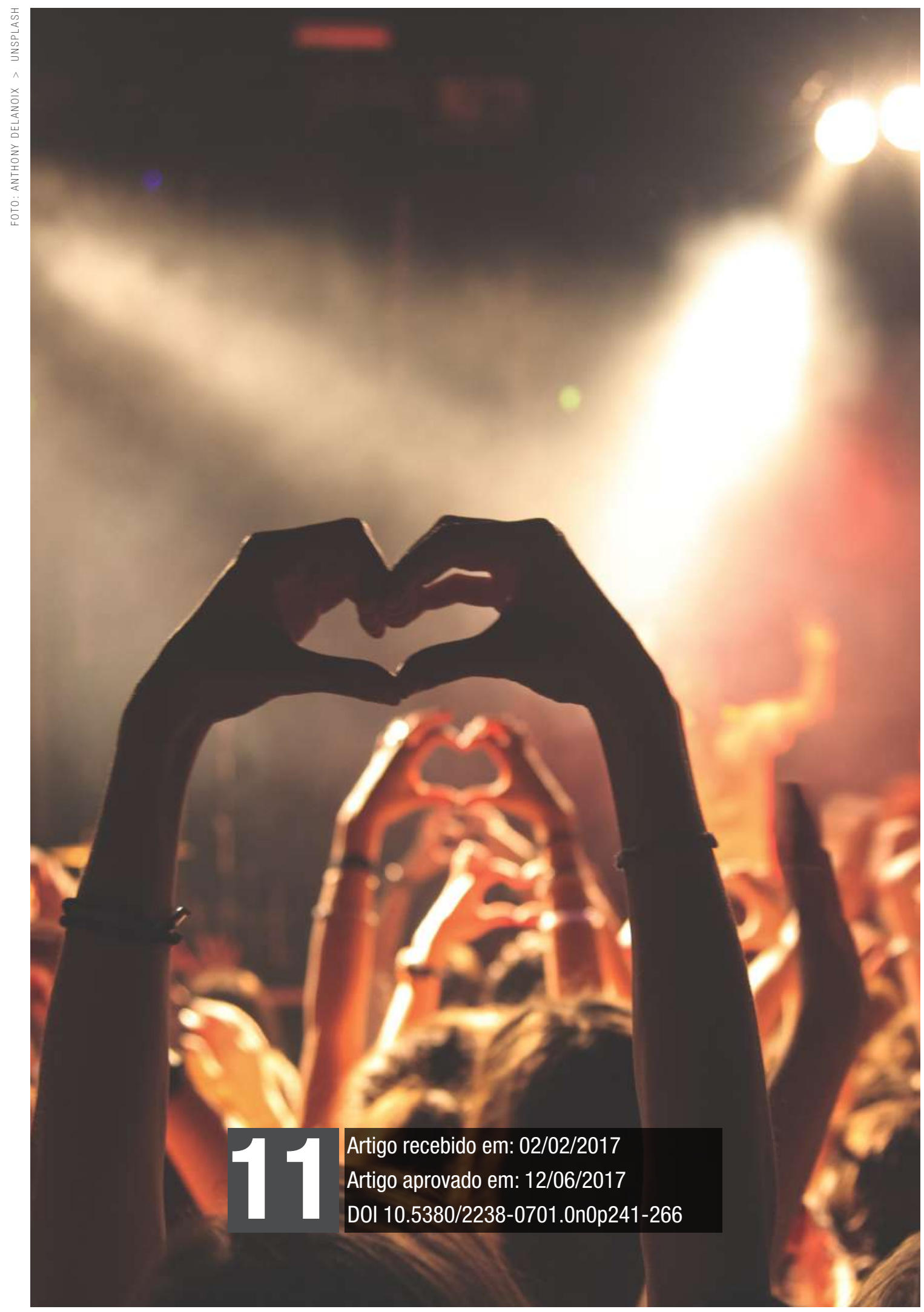


Comunicação midiática. Ídolos. Cultura Fan. 


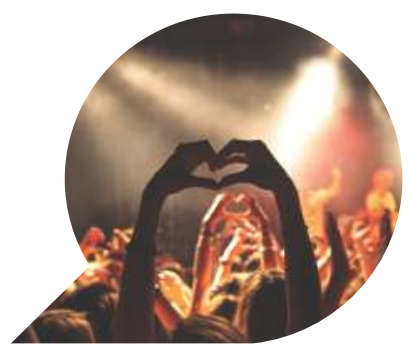

\title{
El Fenómeno Fandom: realidades de ciertos grupos de fans en Guayaquil, Ecuador
}

\author{
O Fenômeno Fandom: realidades de certos grupos de fãs \\ em Guayaquil, Equador
}
The Fandom Phenomenon: realities of certain groups of fans in Guayaquil, Ecuador

ANDREA VAZQUEZ MARTÍNEZ ${ }^{1}$

ELIER GONZÁLEZ MARTÍNEZ²

ALBA ISABEL SELLÁN JÁCOME

Resumen: Comprender el fenómeno fan y sus posibles formas de manifestación en la actualidad constituye un tema de atención para los estudios sociales, sobre todo, por los diferentes enfoques con los que se

\footnotetext{
${ }^{1}$ Licenciada en Psicología en la Universidad de Salamanca. PhD. Doctora en Psicología. Docente-Investigadora Titular de la Universidad Politécnica Salesiana de Ecuador. Miembro del CIS Coordinación Investigación Superior. Miembro de InterTech-Universidad Politécnica de Valencia (España). E-mail: avazquez@ups.edu.ec

2 Licenciado en Estudios Socioculturales de la Universidad Agraria de La Habana. Master en comunicación y cultura) en la Universidad Católica de Louvain-la-Neuve. Doctorante en Información y comunicación en la Universidad Católica de Louvain-la-Neuve Profesor Titular de la Universidad Politécnica Salesiana de Ecuador. Coordinador del Grupo de Investigación en Comunicación e Interculturalidad (GICOI).E-mail: egonzalez@ups.edu.ec

${ }^{3}$ Licenciada en Comunicación Social con mención en producción audiovisual y multimedial de la Universidad Politécnica Salesiana de Ecuador. E-mail: asellan@ups.edu.ec
} 
ha abordado la problemática. La siguiente investigación propone una aproximación a ciertos fandoms guayaquileños, para ello se analizó cómo se autodefinen los miembros de ciertos grupos fans de la ciudad de Guayaquil y qué significa ser parte de ellos. Se aplicaron encuestas a una muestra de sus miembros y se participó en diferentes actividades organizadas por las comunidades de fans. Se constató que se reconocen como pequeñas y grandes comunidades con objetivos y planes para fortalecer el trabajo en equipo, contradiciendo diversos estereotipos sociales.

Palabras claves: Comunicación mediática; Ídolos mediáticos; Cultura fan; Fandoms.

Resumo: Entender o fenômeno fã e suas possíveis formas de manifestação, hoje, é um tema em foco nos estudos sociais, sobretudo, por meio de diferentes enfoques com os quais têm abordado a problemática. A presente pesquisa propõe uma aproximação com certos grupos de fandoms guayaquilenhos, para tanto, foi analisado como se autodefinem os membros desses grupos fãs da cidade de Guayaquil e o que significa para eles fazer parte desses grupos. Entrevistas foram aplicadas a uma mostra de seus membros e foi realizada observação participante em diferentes atividades organizadas pelas comunidades fã. Constatou-se que se reconhecem como pequenas e grandes comunidades com objetivos e planos para fortalecer o trabalho em equipe, contrariando vários estereótipos sociais.

Palavras-chave: Meios de comunicação; Ídolos midiáticos; Cultura de fãs; Fandoms.

Abstract: To understand the fanaticism, and its possible forms of expression today, constitutes a focus for the social sciences, especially for the different methods of study analyzed by the fans and their groups. This research proposes an approach to diverse fans club in Guayaquil, contemplating the analysis of the self-definition of members of some of these fan clubs and what to be part of their group means to. A survey was conducted among some of the members and the researchers participated in different activities held by these groups. It was verified that each group considers itself as a small or even big community, sets scopes, organizes plans and meetings to strengthen team work opposing to typical social stereotypes.

Key-words: Mass media; Celebrities and social media people; Fan culture; Fandoms. 


\section{Breve aproximacíon a la problemática de estúdio}

En las distintas épocas de la historia se han conocido ídolos que se han destacado por su sabiduría, poder, cualidades o talentos, y por generar en las sociedades sentimientos de afinidad e inspiración; naciendo de ello el fenómeno fan. En todas las sociedades son necesarios referentes conductuales que guíen a la población. Los ídolos han sabido influir en la mente de las distintas civilizaciones construyendo patrones o hábitos de conducta, con el fin de que todo ciudadano sueñe con alcanzar el mismo nivel de fama y reconocimiento (ÁLVAREZ-GANDOLFI, 2015; BORDA, 2015; BOUSQUET, 2010; SANTILLÁN GARCÍA, CORNEJO MARROQUÍN, AUSÍN LOMAS, 2012).

Por otro lado, las posibilidades y oportunidades de alcanzar la fama o de conocer a ídolos, se han multiplicado gracias a las puertas que han abierto las comunicaciones a través del desarrollo de tecnologías como Internet (BARNES, 2015). Los fans ya no se limitan a admirar desde lejos, su contacto es más cercano a la realidad del ídolo o en su defecto, pueden participar de grupos cercanos a él (BENNETT, 2006; GUERRERO-PICO, 2015; MUDRICK, MILLER, ATKIN, 2016).

Para Busquet (2012) la fama es un elemento comunicativo básico, una tarjeta de presentación, un fenómeno estructural y un elemento imprescindible para entender la dinámica de los individuos que compiten por un espacio en el mercado del interés público creado por la realidad mediática. Deja abierta a la comprensión de los lectores y analizadores no sólo el alcance del fenómeno fan en la población, sino que el origen de los ídolos mediáticos puede venir, de hecho, desde meros ciudadanos comunes. Nos encontramos en la capacidad de, admirar un ídolo mediático o de convertirnos en uno, y ahí coexiste el poder de la elección: ser un seguidor o ser el ídolo admirado.

La incidencia del fenómeno fan se identifica de manera individual y colectiva, identificando en nuestros contextos a fanáticos aislados, $\mathrm{u}$ organizados por grupos. Un fandom no viene formado por una histeria colectiva de naturaleza juvenil o meramente alineada a una locura adolescente, con la explicación y ejemplos de su teoría es posible abordar la sustentación teórica de las diferentes formas que toma el fenómeno fandom, pudiendo así, romper diversos estereotipos creados alrededor de su desarrollo (RODRIGUEZ G., 2006). Gracias al aporte de Rodríguez, se incluye un nuevo término a considerar dentro de la investigación: cinéfilos, grupos de fans presentes en el ámbito del cine; fanzine, grupos 
de fans en el mundo de la prensa escrita o su variante en la web (en cuyo caso se denominan webzine) ampliando las categorías de análisis disponibles para la obtención de conclusiones más específicas y efectivas.

Juan Sardá Frouchtmann (2014), desde una perspectiva testimonial, aborda el significado de una vida como fan que va más allá de un estereotipado modo de vida (como muchos tienden a catalogarlo) sino como un significativo modo de vida para el sujeto, que se encuentra apto para sustentar sus razones; aspecto poco conocido e influyente en la estigmatización del fenómeno. La razón de por qué son mal catalogados los grupos de fans, recae en el hecho de que han sido presentados a la sociedad como sujetos aislados, poco sociables, extraños y de ser llamados "friquis" (GUERRERO-PICO, 2015). Este amplio panorama no tendrá un significado equilibrado, si no se analizan las diferentes formas de manifestación e interpretación del fenómeno fandom.

La presente investigación surge como inquietud personal ante el poder que el fenómeno fan genera en la sociedad ecuatoriana, específicamente en la ciudad de Guayaquil, coincidiendo con lo expresado por BUSQUET (2012) "sector del público muy dinámico y cada vez más atractivo para las industrias creativas" (p. 27). El estudio encuentra espacio de desarrollo en el Grupo de investigación en comunicación e interculturalidad (GICOI) de la Universidad Politécnica Salesiana del Ecuador UPS.

Ecuador no se excluye de esta influencia cultural y cuenta con la presencia de fandoms representativos cuyas acciones los han convertido en verdaderas comunidades. La mayor parte de los grupos de fans suelen mantenerse como un fenómeno minoritario y con frecuencia estigmatizado. Ante esta constatación, el objetivo del estudio es analizar cómo se autodefinen los miembros de ciertos grupos fans de la ciudad de Guayaquil y qué significa ser parte de él.

En revisiones literarias previas se constata, que el territorio ecuatoriano adolece de investigaciones enfocadas a estos sectores sociales. Sin embargo, es necesario su análisis porque complejizan el entramado social ecuatoriano, donde se aboga por una sociedad intercultural. No reconocer estas minorías, sería obviar el mosaico de culturas y subculturas que conforman al Ecuador. Específicamente, se analizarán grupos de la ciudad costeña de Guayaquil. 


\section{Metodología}

Se identificaron trece fandoms guayaquileños que cumplieron los siguientes requisitos: permanencia dos años, participación periódica o eventual, realizar actividades de socialización y/o eventos de reunión, poseer cuentas en redes sociales básicas (Facebook, Twitter, Instagram) y otras alternativas (páginas de la web) y por último concebir algún tipo de estructura organizativa que los represente y lidere como grupo.

Con una población de 159 personas, un nivel deseado de confianza del 95\% y el margen de error del 5\% los cálculos estadísticos arrojaron la muestra conformada por 98 fans pertenecientes a diferentes fandoms (Ver Tabla 1), quienes fueron encuestados y analizados en diferentes actividades organizadas durante el período abril-diciembre del 2016: reuniones para ver la transmisión en vivo de capítulos, proyectos con instituciones, convenciones locales; intentando realizar una interpretación de sus prácticas grupales:

Tabla 1: Grupos de fans identificados y analisados

\begin{tabular}{cc}
\hline Fandoms & Como se denominan \\
\hline The Walking Dead & Walkers \\
Santiago Cruz (Cantante) & - \\
Big time Rush & Rushers \\
The maze runner & Larchos o Gladers \\
Noel Schajris (Cantante) & - \\
Super Junior & Elf, Kpopers \\
Ricardo Arjona & - \\
Pink & Fuckers \\
Harry Potter & Potterheads \\
Justin Bieber & Believers \\
\hline
\end{tabular}

Fuente: Elaboración própia

Esta investigación se enmarcó dentro de un alcance descriptivo, identificando y especificando las diferentes características de ciertos grupos de fans en la ciudad de Guayaquil. De acuerdo a los avances descubiertos dentro del proceso investigativo se logró también esclarecer cómo y por qué se manifiestan estos grupos de forma independiente a aspectos relacionados con la edad, estrato social o nivel académico.

Las técnicas utilizadas para abarcar los aspectos cualitativos de esta 
investigación fueron: la observación participante, entrevistas y focus group realizadas con los miembros de fandoms reunidos para este estudio. A través de la observación participante se tuvo la oportunidad de conocer a fondo sus actividades, y se descubrió que son capaces de organizar macro eventos independientes de gran afluencia y difusión; son contratados por instituciones públicas o privadas de su sector para eventos sociales en los que pueden dar a conocer su afición, además de realizar proyectos independientes con el mismo objetivo. Las redes sociales se conforman como las herramientas principales de los fandoms, por ello se realizó un monitoreo constante de sus publicaciones, incluyéndonos en sus cuentas de WhatsApp, Instagram, Twitter y Facebook.

\section{Marco teórico}

Etimológicamente el concepto fanático se deriva del latín fanaticus e históricamente hace referencia a aquellos servidores de los templos en los que se adoraban distintas deidades. El concepto de fanatismo se concibe desde una cultura de adoración religiosa que con el tiempo se derivó en otros tipos de admiración: intelectual, política, o social. Y así en la actualidad se pueden categorizar a los fans en distintos movimientos o agrupaciones dentro de la sociedad (BUSQUET, 2012).

Pero, qué es el fan sin su motivo de admiración: el ídolo, no podría concebirse como tal y cada uno coexiste dependientemente del otro. El concepto ídolo se deriva de las palabras idolatría e idólatra que provienen etimológicamente de los compuestos griegos éidolon, que significa "imagen” y latréuo que referencia a la acción "adorar o venerar". El ídolo se alza como la adoración del fanático, ésa que buscará expresar en cualquier forma, independientemente si el ídolo es cercano o lejano a su realidad tangible. La idolatría o éidololátresse define a una persona que "adora las imágenes" referenciado al término actual: el fan; de la misma forma que eidololatréia designa el "culto de las imágenes" (BETTINI, 2015, p.130). El culto a los ídolos ha evolucionado con el paso de la historia sin perder su esencia principal. Para el fanático, el ídolo posee características dignas de emular y necesarias para su enriquecimiento personal y social (KIM; KIM, 2017). Un fanático busca ser igual o al menos parecerse a su ídolo, intenta alcanzar la fama de la cual goza para así formar parte del mundo privilegiado en el que le ha tocado vivir a él, formar parte de su mundo.

Estudios acerca de la fama (GAMSON, 2015; LANG, 2015; THO- 
MAS-JONES, 2010) muestran las diversas formas que ésta adopta en las sociedades mediáticas. Para (ENSEÑAT GUERRA, 2014) se pueden clasificar en tres: la primera agrupa aquellas personalidades que se destacan por cargos de responsabilidades relevantes y que conforman la denominada élite de poder. En contraposición, el segundo tipo de fama está conformado por la élite sin poder, en donde destacarían los artistas, científicos, o deportistas que sin tener ningún poder real consiguen protagonismo mediático y se convierten en modelos de referencia para la mayoría de la ciudadanía. Finalmente, la gente normal cuya aparición más o menos continuada en los nuevos medios de comunicación (por ejemplo YouTube) les permite gozar de la fama en una forma igualitaria por participar en programas de consumo masivo dirigido a un público.

Las ventajas que brindan las nuevas tecnologías comunicacionales vuelven más sencillo (y posible) el adentrarse en el mundo mediático, convirtiendo a cualquier ser humano en una web celebrity, pudiendo incluso, llegar a ser reconocido por los medios tradicionales (BOUFRANCH, GARCÉS-CONEJOS BLITVICH, 2014; GARDNER, LEHNERT, 2016). Un ejemplo de ello son algunos cantantes de covers, bailarines o coreógrafos, actores o humoristas, poetas, escritores; todos quienes forman el conocido grupo denominado youtubers, una extensión de ídolos que ya cuentan con un gran número de admiradores alrededor del mundo (BEERS FÄGERSTEN, 2007).

La literatura reconoce los primeros estudios realizados sobre el fenómeno fan en los EEUU, por la década de 90, donde los catalogaron como "multitudes histéricas o solitarios obsesionados" (JENSEN, 1992). Postura, que los describió como personas con problemas patológicos, comportándose como inadaptados sociales y reproduciendo las características de las sociedades de masa manipuladas por los mensajes mediáticos. Sin embargo, en Latinoamérica estos análisis son aún precarios, y según (ÁLVAREZ-GANDOLFI, 2015; DENNEN, 2014) es un campo de estudios aún por conformar. Borda (2015) resume de la obra de Henry Hensky, diferentes niveles de fanatismo:

a) un modo de recepción que se caracteriza por permitir la coexistencia paradójica de "proximidad emocional" y "distancia crítica”, b) el ejercicio de prácticas críticas e interpretativas que lo alejan de la información estrictamente recibida en el texto primario, c) el hecho de que el fanatismo constituiría una base para el activismo consumidor: las y los fans se sienten consumidores con derecho sobre los avatares de 
los productos/textos que los convocan y, en consecuencia, emprenden acciones diversas de reclamos hacia la industria; d) la producción de textos según determinadas tradiciones estéticas, e) la creación de comunidades sociales que el autor califica de "alternativas": el "mundo de fin de semana”. (BORDA, 2015, p.72)

Estos niveles muestran, como los fans han adquirido un protagonismo y cierta visualización frente a las industrias culturales. Es necesario reconocer el papel que juegan las redes sociales y las diferentes plataformas creadas para que interactúen ídolos y seguidores ${ }^{1}$ (HIDALGO-MARÍ, SÁNCHEZ-OLMOS, 2016).

Ejemplos como estos evidencian el comportamiento activo de culturas participativas mencionado por Jenkins (2008), añadiendo que están íntimamente relacionadas con el concepto de inteligencia colectiva y el nuevo sistema de información. Los usuarios comparten conocimientos y contenidos individuales que se complementan entre si y conforman una nueva fuente de poder mediático (FACUNDO; RE, 2014). Lo que nos lleva a una nueva perspectiva de análisis de los fandoms como comunidades virtuales inteligentes, independientes y con poder contrario a la visión estereotipada con la que mayoría tiende a identificarlos o definirlos. Jenkins (2008) plantea la posibilidad de una mayor permanencia de dichas comunidades fanáticas virtuales al ser concebidas dentro de un carácter de participación voluntaria, temporal y táctica; afirmada mediante objetivos e inversiones emocionales comunes con la apertura de pertenecer a más de una comunidad a la vez.

Desde la opinión de Busquet (2012) tres etapas caracterizan los estudios sobre los fans y pueden ser definidas como: 1) estereotipo social, caracterizada por concebir al fan con un comportamiento patológico de personas que mantienen una conducta irracional y caótica; 2) estudio del fenómeno fan como una vocación descriptiva y comprensiva, en esta etapa se aprecia la inclusión de otros grupos etarios y se comienzan a reconocer la formación de grupos entorno a un mismo ídolo; 3 ) los análisis se organizan con una perspectiva hermenéutica y se reconocen valores colectivos y comportamientos cargados de significados simbólicos de los grupos.

Durante la investigación aún se constatan opiniones y percepciones

\footnotetext{
${ }^{1}$ Un ejemplo vivido durante la investigación, fue cuando el ídolo juvenil Justin Bieber cerró su cuenta de Instagram, todas sus fanáticas, las beliebers expresaron sentirse tristes y decepcionadas, pero confiaban que cuando su nueva novia lo abandonara, él regresaría con ellas. Sin embargo, las chicas de este grupo manifestaron que "estarían ahí, fieles" para cuando el artista las necesite.
} 
variadas que pueden ser agrupadas en cualquiera de los tres momentos anteriores. Guayaquil, aunque es una ciudad cosmopolita, arrastra posiciones conservadoras para con el fenómeno en cuestión, reduciéndolos a minorías conflictivas y sin personalidad propia, que intenta vivir su vida a través de sus ídolos².

El fanatismo está ligado con procesos culturales, y está compuesto por tres elementos principales: cultura de masas, adolescencia y feminidad (SARDÁ FROUCHTMANN, 2014). Sin embargo, el autor reconoce que los dos últimos aspectos en las sociedades actuales no son representativos del fenómeno. Los hombres a través de sus jugadores de futbol, personajes guerreros de las películas o los personajes de los comics también están manifestando actitudes similares a los comportamientos femeninos criticados por décadas.

Otros aspectos reconocidos por (SARDÁ FROUCHTMANN, 2014) y encontrados en estudios como (DOYLE et al., 2016; HSU et al., 2015; REIJNDERS, 2011) muestran la fabricación acelerada y veloz de fans por la influencia mediática y la necesidad que tienen de adaptarse a la oferta de ídolos mediáticos. Sin embargo, también existen personas que consagran su idolatría a una sola persona u objeto (VIERA ALCAZAR, 2013)

En conversaciones sostenidas con adolescentes se observaron ambas posturas, donde admiraban varios ídolos a la misma vez. Sin embargo, no se considera representativa la presencia de personas mayores. Estos, adoptan posiciones más conservadoras y si bien su fanatismo es admirable por la dedicación y seguimiento en el tiempo, practican otras formas: transmisión oral de sus ideas, coleccionismo que se convierten en el patrimonio tangible e intangible de la familia, incluso de amigos hasta comprar entradas a conciertos en posiciones privilegiadas que les permita disfrutar en tranquilidad de su ídolo (GARCIA, 2011).

\section{Análisis de resultados}

Se identificaron 159 personas como población de la investigación, sin embargo la muestra seleccionada fue de 98 participantes que respondieron al cuestionario administrado a través de Google Drive. Características generales de la muestra pudieron identificarse a través de la primera, segunda y tercera incógnita, agrupándose de la siguiente forma (Ver Tabla 2):

\footnotetext{
${ }^{2}$ Resultados preliminares obtenidos en investigación de campo realizada a una muestra de personas no fans de la ciudad de Guayaquil y que está en proceso de tabulación y análisis de resultados. Autores: Alba Sellán y Elier González
} 
Tabla 2: Características de los participantes

\begin{tabular}{lcc}
\hline Características & Cantidad & Porcentaje \\
\hline Edad & 9 & \\
$10-14$ & 59 & 9,2 \\
$15-19$ & 29 & 60,2 \\
$20-30$ & 1 & 29,6 \\
Más de 31 & & 1 \\
\hline Género & 83 & 84,7 \\
Mujer & 15 & 15,3 \\
Hombres & & \\
Se considera fanático & 95 & 97,1 \\
Sí & 2 & 2.1 \\
No & & \\
Pertenencia a un grupo fan & 82 & 83,7 \\
Sí & 16 & 16,3 \\
No & & \\
\hline
\end{tabular}

Fuente: Elaboración própia

En las respuestas se puede observar aspectos como: existen fans mayores de 31 años, población poco habitual, porque la inversión emocional puesta durante la adolescencia sobre un fan puede continuar pasados los 30 años, pero su permanencia dependerá de lo que continúe significando durante el desarrollo del resto de su vida (BENNETT, 2006); el mayor porcentaje pertenece al sexo femenino, siendo una tendencia habitual observada en los estudios (GUERRERO-PICO, 2015); y finalmente, la mayoría son fanáticos y pertenecen a un grupo fan.

Con la cuarta incógnita se demostró el gran porcentaje de encuestados pertenecientes a fandoms en la actualidad, donde un $83.7 \%$ pertenecen a un grupo (Gráfico 1) mientras que solo un $16.3 \%$ no pertenece. Al contrario de muchos otros que prefieren ser independientes $y$ mantener su admiración en privado frente, otros deciden agruparse con personas de gustos comunes. En nociones de Alejandro Grimson (2011) se afirma que toda cultura está compuesta por tramas compartidas de significación y prácticas procesuales de producción simbólica que construyen un "nosotros" distinto de "otro" (ÁLVAREZ-GANDOLFI, 2015). El estudio se enfrenta ante una realidad diversa de comportamientos asociativos por parte de los fans. 
Gráfico 1: Pertenencia a grupo fandom

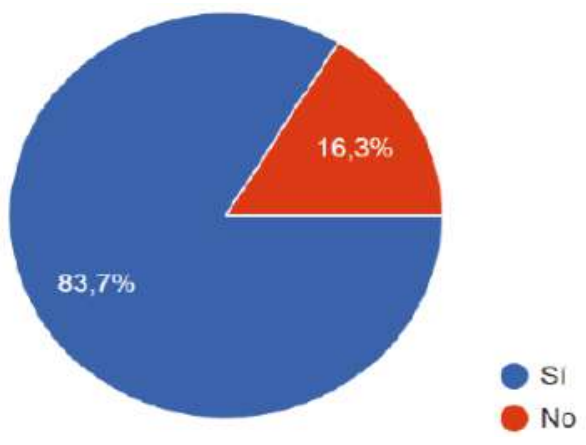

Fuente: Elaboración própia

La fanatización es una cuestión de intensidad (BOUSQUET, 2010) y con la quinta pregunta se solicitó al fan calificar su nivel de admiración: siendo 1 el nivel mínimo y 5 el nivel máximo de admiración. Se utilizó para su medición una pregunta en forma escala de Likert, utilizando la variable "admiración", definida por (BOUSQUET, 2010) como unos de los elementos fundamentales para comprender el grado de fanatismo de un individuo. El segundo gráfico muestra que cerca del 79,6\% de los encuestados se ubica en el nivel máximo y solo el $2 \%$ de los encuestados se ubica en el nivel mínimo. Dicho cuestionamiento permite reconocer dentro de la muestra con qué nivel de admiración se reconocen los fans encuestados, más allá de analizarlos como personas aisladas o multitudes histéricas como lo propone Joli Jensen en su corpus mediático (BORDA, 2015)

Gráfico 2: Nivel de fanatismo

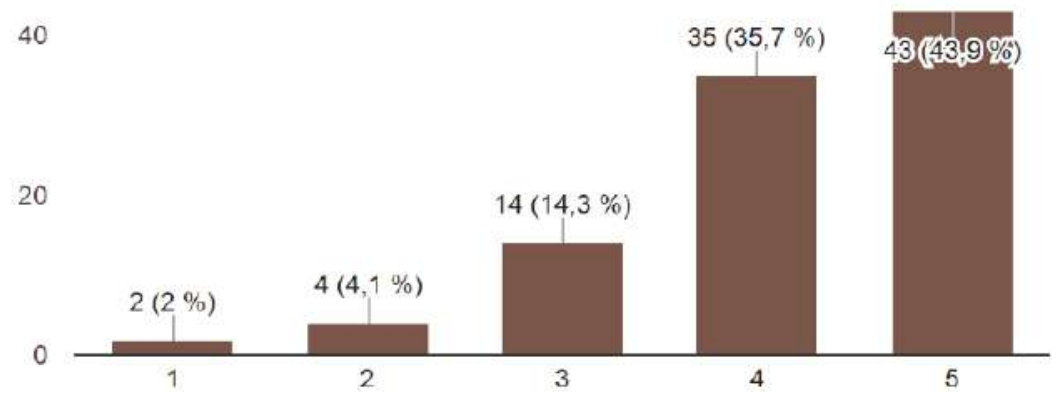


En la sexta pregunta se indagó los motivos con los cuales los fans se sienten identificados y reveló que un 51.5\% admira la "manera de vivir y ver las cosas" y solo un 3.1\% de elección seleccionó el físico del sujeto o entorno del objeto admirado (Ver Gráfico 3). Este análisis aporta el predominio de una realidad subjetiva sobre una realidad objetiva que comúnmente se asigna al comportamiento fan. Un ejemplo vivido durante la investigación fue el impacto generado sobre la audiencia de fans walkers (público de la serie estadounidense The Walking Dead) quienes literalmente "sufrieron" con el asesinato de dos personajes "muy queridos" al regreso de la séptima temporada y manifestaron sentirse "traicionados, desilusionados" con toda la producción y dirección del programa, al no tomar en cuenta el dolor que provocaría la decisión de desaparecer de la historia y del elenco dichos personajes.

Gráfico 3: Afinidad con el ídolo

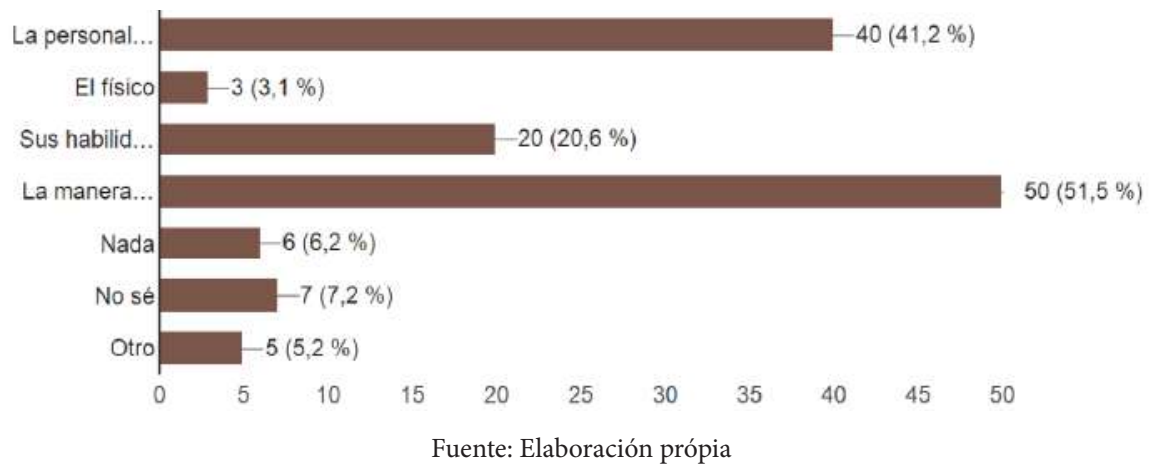

La diversidad de motivaciones identificada puede asociarse con la dialéctica de valor propuesta por Matt Hills en donde explica que el fanatismo tendría un carácter subjetivo debido a la adjudicación de valores intensos, asociado con dinámicas más generales y estructurales de generación de valor de cambio (BORDA, 2015).

Otro dato interesante que suscitan estos resultados, es la poca atención que brindan al cuerpo físico de sus ídolos. Al participar en los focus group con fans de diferentes grupos, reafirmaron su preferencia por la forma de pensar su ídolo y la vida como la viven, declarando no importarle su apariencia física o los kilos de más que puedan tener.

En la séptima consulta se pretende conocer si las críticas negativas hacia el sujeto-objeto admirado por el/la fan le afecta física, mental o emocionalmente en su desenvolvimiento cotidiano. La cuarta figura de- 
muestra que el nivel más alto de encuestados, representado en un 31.6\% del total seleccionó "me es indiferente" y solo el $2 \%$ de los encuestados reveló sentirse nervioso, aunque otro porciento representativo confesó sentirse mal o que al rato se le pasaba (Gráfico 4). Sin embargo, en diferentes actividades con ellos, se observó, como en ocasiones, un mismo personaje de una serie puede provocar discusiones entre los fans, reflejando una mirada crítica o sobreprotegida en la conducta seguida hacia sus ídolos.

\section{Gráfico 4: Sentimientos hacia el ídolo}

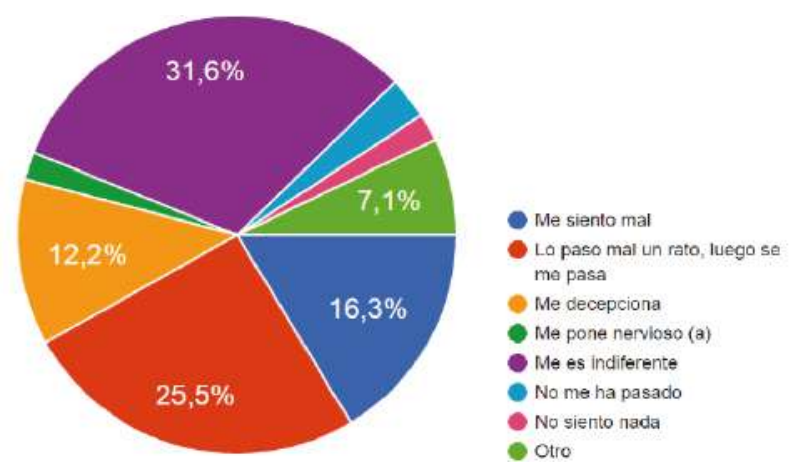

Fuente: Elaboración própia

De forma complementaria a la séptima pregunta se cuestionó en la pregunta catorce si los fans establecen relaciones con personas fuera de su grupo o medio (no fans) arrojando un 79,6\% de respuestas afirmativas y solo un $20.4 \%$ que mantiene esa exclusividad relacional (Gráfico 5).

Gráfico 5: Aficiones con el ídolo

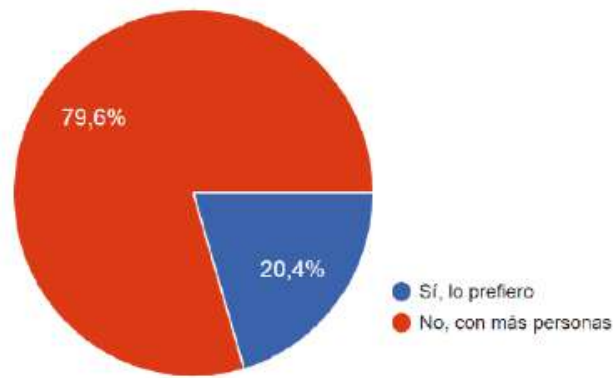

Fuente: Elaboración própia 
Dicho resultado puede sustentarse en la postura de Mead y Passmore donde se plantea el fanatismo como un fenómeno social donde la presencia de otros fanáticos desempeña un papel importante en su sustento o desarrollo. En estudios de Julien Bousquet el fanático se alimenta de otros fanáticos siendo el entorno (amigos y familia) un elemento inevitable en el desarrollo idéntico del fanático. A diferencia del estereotipo de aislamiento señalado equívocamente en fans, el deseo de interacción social se vuelve entonces inevitable en su compromiso (BOUSQUET, 2010).

Con la octava incógnita se constata, a través del Gráfico 6, que el $79.4 \%$ de los fans considera a su sujeto-objeto admirado como una referencia personal mientras un $20.6 \%$ sólo le admira independientemente del modelo que transmita como persona u objeto, dejando abierta la posibilidad de conocer otros motivos superficiales de admiración, algunos propuestos en la novena pregunta.

Gráfico 6: El ídolo como referente personal

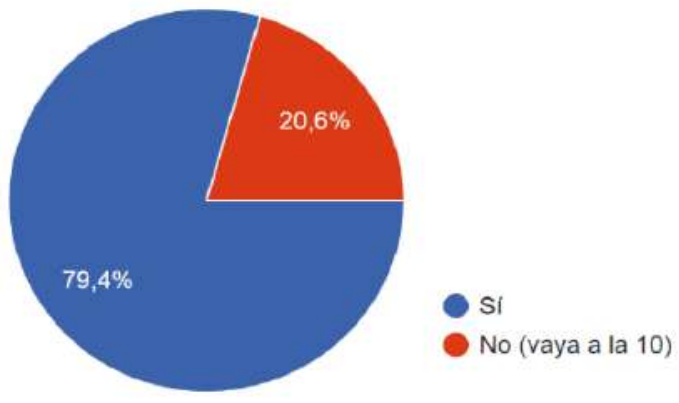

Fuente: Elaboración própia

"Por el esfuerzo que demuestra" fue el motivo más seleccionado por los fans, marcando un 57\% de elección (Gráfico 7). Ninguno de los encuestados seleccionó el motivo económico y sólo un $2.5 \%$ seleccionó la apariencia física del sujeto-objeto admirado, demostrando que los fans basan su admiración en características más profundas a la posesión de bienes materiales, estatus económico o apariencia física. El fanático no es un ser irracional, tal vez de mente cerrada e intolerante pero es consecuencia de la pasión propia de sus comportamientos que siempre influirá en su manera de ver las cosas (BOUSQUET, 2010). La admiración en los fans se da de manera consciente vinculada a su realidad y a los 
valores que aplica o busca imitar para su vida. Su sentimiento de admiración va más allá de la fama banal que ostenta el ídolo como producto de su oficio, el fan se siente vinculado con la versión humana que (desde su visión y sentimiento) no se transmite realmente frente a cámaras. Para el fan su ídolo es más que un personaje famoso, es un ser humano con cualidades excepcionales dignas de admirar o venerar.

Gráfico 7: Motivos de admiración

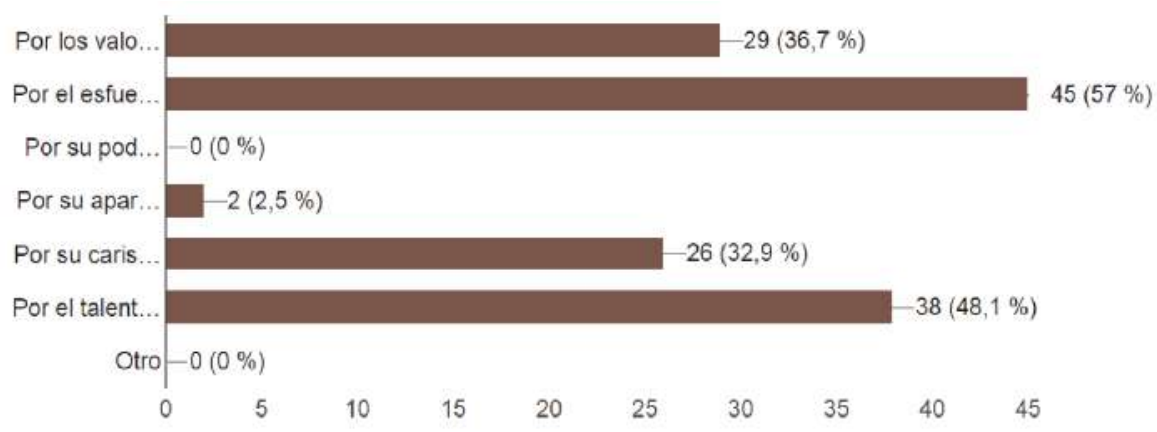

Fuente: Elaboración própia

Con la consulta número diez se pretendió conocer si el sujeto-objeto aporta conocimientos significativos a la vida del fan. Más de la mitad de la muestra seleccionada respondió afirmativamente, marcando un $53.6 \%$ de respuestas (Ver Gráfico 8). Hills (2002) y MacKellar (2006) expresan que el grado de conexión de un fan es causado por distintas motivaciones y una de ellas es demostrar un determinado conocimiento en el ámbito de actividad privilegiada para el placer de encontrar el objeto como único (BOUSQUET, 2010, p. 179).

Gráfico 8: ¿Aprendemos con nuestros ídolos?
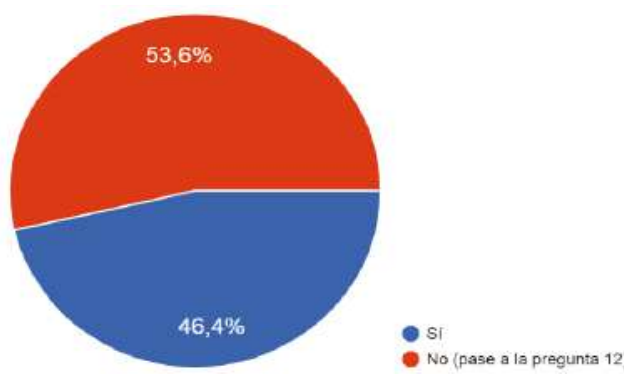
Pero un porcentaje igual de representativo respondió negativamente, marcando un $46.4 \%$ de respuestas, demostrando que puede existir una mayor diversidad al hablar de motivos de admiración. Dicho cuestionamiento se vincula con la pregunta once en donde el objetivo fue conocer si existe algún patrón de elección repetitivo frente a lista de motivos propuestos.

Las respuestas obtenidas se organizaron en 4 categorías, en función de patrones identificados: aptitudes y actitudes, valores, idiomas, otros (Ver Tabla 3). Dentro de la categoría de aptitudes y actitudes los fans expresaron que la mayor parte de conocimientos escogidos les ayudan a mejorar como persona y enfrentar su desarrollo con la sociedad. En la categoría de valores, los fans coincidieron en que su sujeto-objeto les transmite características positivas como madurez, fortaleza, amistad, perseverancia, seguridad, honestidad, humildad, unión familiar y fidelidad, entre otras; confirmando que " un fan puede convertir en un emblema cualquier estigma” (ÁLVAREZ-GANDOLFI, 2015, p. 49).

Tabla 3: Motivos propuestos

\begin{tabular}{|c|c|c|c|}
\hline APTITUDES Y ACTTTUDES & VALORES & IOIOMAS & OTROS \\
\hline Conocimiento cultural & respuesta "valores" (en generai) (3) & respuesta solo "idiomas' en general (3) & $\begin{array}{l}\text { referencias en mi estilo } \\
\text { de hacer música }\end{array}$ \\
\hline cosas interesantes que no sabia & percepción madura de la realidad & coreano & $\begin{array}{l}\text { depende del punto de } \\
\text { vista del programa }\end{array}$ \\
\hline todo lo necesario que necesito saber & $\begin{array}{c}\text { fortaleza } 3 \text { (sentirme segura conmigo misma), } \\
\text { fuerza de voluntad }\end{array}$ & en música & \\
\hline creatividad (2) para estudio y trabajo & amistad $y$ hermandad & $\begin{array}{l}\text { aprender mejor el idioma, pronunciación, } \\
\text { habla, }\end{array}$ & \\
\hline información y relación con estudios & mejarar como persona & aprender y comprender el idioma & \\
\hline $\begin{array}{l}\text { Analisis de situaciones determinadas con sus } \\
\text { diferentes formas de proceder o interactuar. }\end{array}$ & honestidad & & \\
\hline $\begin{array}{l}\text { me ayuda en el ambito social y cultura por } \\
\text { medio de convenciones publicas }\end{array}$ & otros & & \\
\hline
\end{tabular}

Fuente: Elaboración própia

"Idiomas" fue una de las categorías más comentadas, siendo el inglés el más seleccionado por los fans. En conversaciones sostenidas expresaron que su admiración e interés por dominar ciertas canciones y textos de los diálogos, les ha permitido potenciar su capacidad de pronunciación y comprensión del idioma.

Se ha comprobado que dentro de las modalidades creativas del fe- 
nómeno fan; el fan fiction (creación de textos escritos por los fans) posee potencial específico como vehículo para el aprendizaje de segundos idiomas: como el inglés (GUERRERO-PICO, 2015, p. 740), comprobando que puede derivar manifestaciones creativas hasta pedagógicas (BARNES, 2015). Otro de los idiomas revelados dentro de esta encuesta fue el coreano, debido a que se encuestó a un fandom K-Pop. Como ejemplo se experimentó durante la investigación la experiencia de una fan elf (fan de agrupación coreana Super Junior) quien decidió llevar su admiración y dominio del idioma coreano hasta su proceso de titulación de carrera universitaria, elaborando una aplicación que permita a otros fans del K-Pop y personas no fans: aprender y dominar el idioma coreano a través de las músicas de sus ídolos favoritos.

En la pregunta doce se solicitó a los fans seleccionar los principales medios de interacción que usan con el sujeto-objeto admirado y/o con su respectivo fandom. Superando a la media establecida, el $90.7 \%$ de fans afirmaron utilizar las redes sociales como se muestra en el Gráfico 9. Las redes sociales han redefinido de tal manera la experiencia de los usuarios en la web que se han constituido como un medio en sí mismo (FACUNDO; RE, 2014, p.35).

Gráfico 9: Medios de interacción con el ídolo

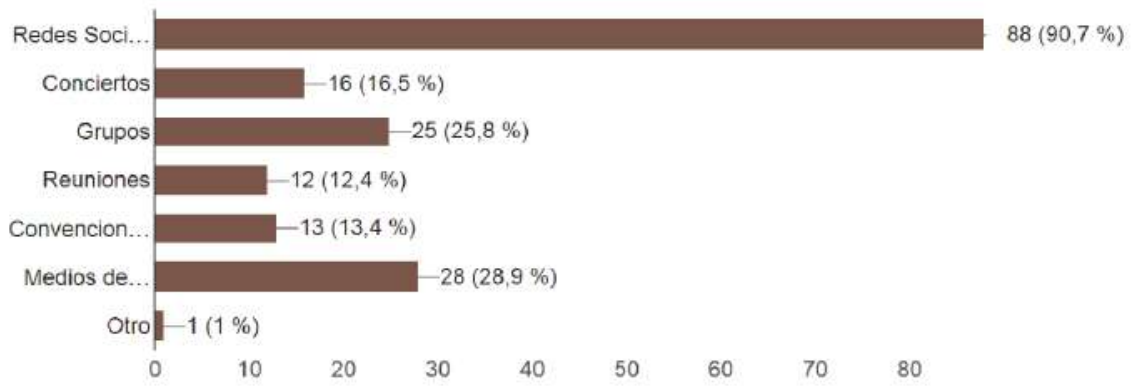

Fuente: Elaboración própia

Por otro lado, el porcentaje menos representativo de respuesta fue la opción de "reuniones" con un $12.4 \%$ del total de muestra encuestada, dichos espacios se realizan en fechas consensuadas por todos los miembros del fandom pero al final se presentan sólo quienes conforman cargos importantes dentro del grupo, ejerciendo liderazgo sobre unos 
pocos que buscan participar más allá del mero entretenimiento aportando de sí mismos algo extra al grupo buscando afirmar su compromiso como fan ante los demás. La comunicación de los fandoms actualmente se manifiesta a través de las herramientas tecnológicas (grupos de WhatsApp o Facebook), pese a no coordinar reuniones dentro de un tiempo periódico, pero logrando altos índices de calidad a las actividades organizadas por el fandom.

La opción "otros" (1\%), deja abierta la posibilidad de análisis para descubrir nuevas alternativas de interacción utilizadas por los fans en la actualidad y que no están establecidas en las categorías contempladas para este estudio, por ejemplo, los rituales sociales que constituyen la base sobre la cual los fandoms sostienen su identidad colectiva y aquello que los define como un 'grupo' en lugar de una simple colección de individuos (ÁLVAREZ-GANDOLFI, 2015, p.52-53).

La pregunta trece indagó, si el fan adopta como propias, la apariencia física o mentalidad (acciones, comportamientos) del sujeto-objeto admirado en su vida cotidiana. El nivel de admiración de algunos fans (ejemplo: caso cosplayers ${ }^{3}$ ) va determinado por el esfuerzo en la inversión hacia la fidelidad, siendo la imitación de características físicas de sus ídolos: la vestimenta, accesorios y hasta rasgos físicos; independientemente de cuánto les cueste el esfuerzo o gasto monetario invertido; "mayor fan para algunos", será aquel que replique a cabalidad la imagen o apariencia física del ídolo.

Algunos fans van más allá e imitan el modo de vida de sus ídolos, pasando a un nivel más abstracto y subjetivo de admiración, en el que se sienten realizados porque logran alcanzar las características más profundas de su ídolo.

Según el Gráfico 10 se pudo constatar que de la muestra encuestada, específicamente el $54.6 \%$, adopta como propios dichos compartimientos físicos o mentales, siendo este, parte de su estilo o accionar. Dicho resultado, puede fundamentarse en la necesidad de construir y representar la propia identidad cultural, relacional y diferente de otro sujetos no fans realizados sobre la base la base de los objetos de la cultura masiva (ÁLVAREZ-GANDOLFI, 2015, p.49).

\footnotetext{
${ }^{3}$ La palabra cosplay proviene del inglés costume play, "juego de disfraces", y la palabra cosplayer remite a los sujetos que realizan dichas prácticas.
} 
Gráfico 10: Adopción de patrones similares con el ídolo

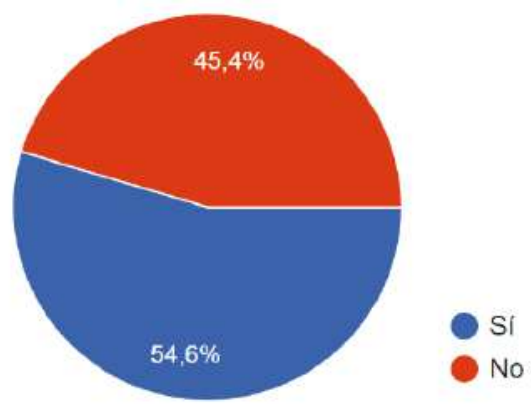

Fuente: Elaboración própia

Por otro lado, el 45.4\% respondió negativamente, demostrando que una representativa proporción de la población encuestada de fans prefiere mantener su admiración al margen de cualquier tipo de imitación. Deja abierta la posibilidad de análisis y exploración de qué otros aspectos se consideran importantes para manifestar el compromiso e identificación con el ídolo.

Finalmente, en la pregunta quince se plantearon diversas alternativas de actividades de socialización realizadas exclusivamente dentro de un fandom. El Gráfico 11 demuestra al 80.4\% de fandoms utilizando principalmente las redes sociales, reafirmando su uso como herramienta esencial y principal. Las respuestas de menor incidencia corresponden a las opciones "Realizamos convenios con entidades públicas o privadas" y "otros". Dichos proyectos les permiten costear gastos internos y principalmente darse a conocer ante la población no fan, de tal manera que encuentren afinidad compartiendo con otros sus gustos e intereses.

Gráfico 11: Actividades de los fans

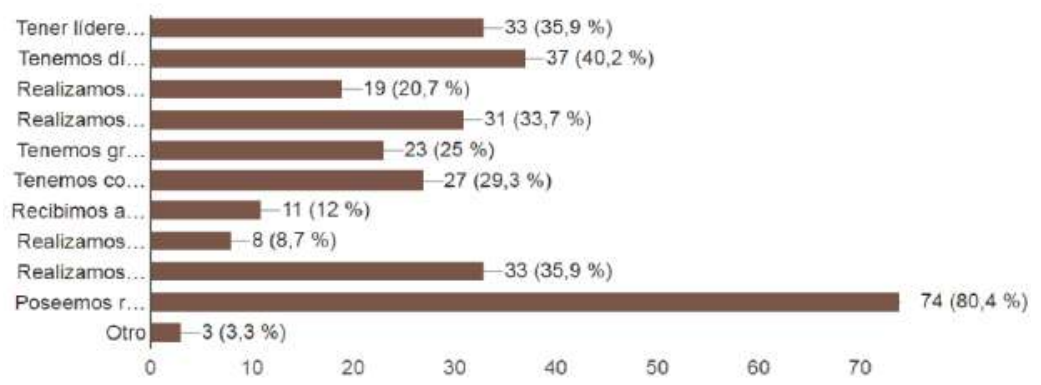


Dentro de los fandoms seleccionados, algunos se destacaron por su organización y participación de diversas actividades y proyectos realizados durante la realización de este estudio. Por ejemplo, el club The Walking Dead Ecuafans participó de un sinnúmero de eventos, entre ellos: $6 K$ The Running Dead, maratón con temática zombie; Monster Fest, expo feria al aire libre en convenio con Fundación Malecón 2000; varias Caminatas Zombie, una de ellas organizada por Centro Comercial Mall del Sol Guayaquil; eventos al aire libre por las fiestas de cantones de la ciudad (Milagro - Durán - Guayaquil); Budokan, Ecuador Comics Weekend 2016 y Comic Con Ecuador 2016, tres de los eventos más importantes del año relacionados con el mundo del cómic en el país, entre muchos otras actividades dignas de admiración por la capacidad organizativa, fidelidad, compromiso y entrega.

Otro destacado fue el fandom de Elfs K-Popers y su fuerte vínculo que las une a sus ídolos coreanos (la mayoría de fans dentro de este grupo son mujeres). Cada mes organizan en conjunto con otros países el envío de cartas, obsequios e incluso, comida en el cumpleaños de un determinado miembro de la agrupación musical Super Junior. Algunos de estos ídolos ejercen el servicio militar durante su carrera artística, por ello las cartas se realizan principalmente, con el objetivo de enviar buenos deseos y cariño en su estancia fuera de los escenarios, acto que reafirma su fidelidad ante la espera del regreso tan ansiado. Como fandom, participan cada año del Hallyu Fest, el festival de la ola coreana, macro evento realizado por la embajada coreana en Ecuador donde se destaca la importancia del intercambio cultural a través de exposiciones artísticas, fotográficas, eventos musicales, gastronomías y más.

En la ciudad de Guayaquil se ha comprobado que los fandoms se muestran dispuestos a ampliar sus horizontes en cuanto a actividades de socialización. Su presencia en la ciudad se hace notar cada vez más, su sacrificio y dedicación ha logrado que cumplan sus metas, a pesar, que los escenarios en ocasiones no son favorables.

\section{Consideraciones finales}

La evolución del contexto histórico-social ha hecho de los fans seres humanos completamente diferentes a la caracterización estereotipada con la que inicialmente eran catalogados. El fan transitó de ser un individuo irracional a ser un ente comprendido por otros iguales a nivel emocional y cognitivo. El fanatismo se extiende a diversas ramas e ideo- 
logías y han surgido diversidad de fanáticos, en comparación al inicial universo conformado únicamente por fans del mundo meramente artístico. Como una necesidad individual y social se organizan los sujetos para lograr una construcción o personificación ideal del ser, en base al modelo o referente social que es el ídolo.

La presente investigación evidenció cómo una misma práctica cultural (fan) ha generado en Guayaquil diferentes identificaciones. Todas estas construcciones identitarias se dan desde la concepción grupal; a través de la creación, reproducción y utilización de símbolos propios que los definen y diferencian. Por ejemplo: aunque en los resultados se constató el predominio de un público joven, se conoció de personas mayores que aún conservan su idolatría por una figura, sin embargo, su fanatismo varía en contraste al de los más jóvenes por la discreción con que manejan sus actos de culto. En la actualidad si realmente se aboga por una sociedad donde prime el diálogo intercultural, debemos reconocer y comprender los diferentes entramados que la componen.

El predominio del género femenino en el comportamiento fan refleja concordancia con diversos estudios. No obstante, algo que prevalece independientemente de la edad, género o posición social de los fans es el sentimiento de fidelidad y el tiempo. Para todo fan es substancial la inversión de tiempo en la admiración del ídolo, es una inversión gratificante para sí mismo. Además, la fidelidad es independiente a la imagen física que transmita el ídolo, para un fan el poder de éste yace en su calidad emocional y en sus cualidades actitudinales ante la adversidad del mundo al que se enfrentan.

El fanatismo no es una práctica histérica y sin sentido, proporciona conocimiento y enriquecimiento personal. Desde la promoción de valores hasta la motivación por el aprendizaje de nuevos idiomas, el fenómeno fandom se sustenta en seres lógicos que se forman y preparan en busca de imitar de la mejor forma posible a su ídolo. Este objetivo conlleva a aprender y aprehender desde comportamientos hasta conocimientos nuevos, que desde su visión, pueden servirle provechosamente para su progreso y aumenta la posibilidad de ser reconocido entre el grupo de fans.

Los medios de comunicación se mantienen como los principales promotores de los íconos o ídolos mediáticos, siendo la televisión y el internet los preferidos por los fans. Estos cumplen el papel de volver al ídolo alguien más humanizado, mitificando sus acciones en función del 
interés social. Por un lado, las nuevas tecnologías comunicativas reducen la distancia entre los ídolos mediáticos y sus fans; particularmente internet, permite a los fans mantener un constante seguimiento de sus ídolos y por ello se convierte en el aliado perfecto para el fanatismo. Este hecho, reconoce nuevas formas de comunicación que se posicionan preferencialmente en las personas para interactuar con su ídolo, contrario a la propuesta de medios convencionales. Por el otro lado, la televisión mantiene su rol determinante dentro de la sociedad y aún conserva una significativa cantidad de adeptos.

Otra de las puertas que abre el mundo de las tecnologías comunicativas es la interacción con grupos diversos de fanáticos y no fanáticos. Gracias al internet, el fan pasó de ser un consumidor pasivo a ser el creador del material de culto de sus ídolos sin dejar su calidad de consumidor fiel. Con talento y esfuerzo muchos fans se consolidan como verdaderos líderes de fandoms, proporcionando y compartiendo material diverso sobre sus ídolos en formatos llamativos para el disfrute de una gran comunidad. El deseo moderno por conseguir la fama impera indirectamente en este accionar y muchos logran convertirse en pequeñas (aunque auténticas) celebridades ante otros fans, a través de sus formas creativas e innovadoras de admirar a su ídolo.

Todos en cierto modo somos fans de algo o alguien porque buscamos complementar nuestra existencia y propósito ante la sociedad sobre la base de un ideal modelo de conducta. Si bien es cierto, diversos aspectos diferencian a los fans actuales de los fans en estudios antiguos, pero el seguimiento interiorizado se mantiene como la característica principal que los identifica. Todo fanático completa sus satisfacciones personales y complementa su realidad social gracias al modelo que ve erguido en su ídolo, quien le permite adecuarse de una mejor manera a la realidad diferente y tal vez menos glamorosa que le tocó vivir.

\section{BIBLIOGRAFÍA}

ÁLVAREZ-GANDOLFI, F. Culturas fan y cultura masiva Prácticas e identidades juveniles de otakus y gamers. La Trama de la Comunicación, v. 19, p. 45-65, 2015.

BARNES, J. L. Fanfiction as imaginary play: What fan-written stories can tell us about the cognitive science of fiction. Poetics, v. 48, p. 69-82, 2015. 
BEERS FÄGERSTEN, K. The role of swearing in creating an online persona: The case of YouTuber PewDiePie. Discourse, Context \& Media, p. 3-27, 2007.

BENNETT, A. Punk's Not Dead: The Continuing Significance of Punk Rock for an Older Generation of Fans. Sociology-the Journal of the British Sociological Association, v. 40, n. 2, p. 219-235, 2006.

BETTINI, M. B. ÍDOLOS E ÍCONOS EN LA SEMIOSFERA MEDIÁTICA. CIC. Cuadernos de Información y Comunicación, v. 20, p. 129-131, 2015.

BORDA, L. Fanatismo y redes de reciprocidad. La Trama de la Comunicación, v. 19, p. 21, 2015.

BOU-FRANCH, P.; GARCÉS-CONEJOS BLITVICH, P. The pragmatics of textual participation in the social media. Journal of Pragmatics, v. 73, p. 1-3, nov. 2014.

BOUSQUET, J. Hacia un acercamiento más contemporáneo del fanatismo deportivo. Revista EAN, n. 69, p. 176-183, 2010.

BUSQUET, J. El fenómeno de los fans e ídolos mediáticos: evolución conceptual y génesis histórica. Revista de Estudios de Juventud, v. 96, p. 13-30, 2012.

DENNEN, V. P. Becoming a blogger: Trajectories, norms, and activities in a community of practice. Computers in Human Behavior, v. 36, p. 350-358, 2014.

DOYLE, J. P. et al. "I was there from the start": The identity-maintenance strategies used by fans to combat the threat of losing. Sport Management Review, 2016.

ENSEÑAT GUERRA, J. F. El fenómeno fan y sus repercusiones en la vida cotidiana. p. 143, 2014.

FACUNDO, P.; RE, A. La política transmediática. 2014.

GAMSON, J. Celebrity A2 - Wright, James D. BT - International Encyclopedia of the Social \& Behavioral Sciences (Second Edition). In: Oxford: Elsevier, 2015. p. 274-278.

GARCIA, M. I. Imagen y recepción de los beatles en la españa franquista. [s.l.] Universidad de Sevilla, 2011.

GARDNER, J.; LEHNERT, K. What's new about new media? How multi-channel networks work with content creators. Business Horizons, v. 59, n. 3, p. 293-302, maio 2016.

GUERRERO-PICO, M. Producción y lectura de fan fiction en la comunidad online 
de la serie Fringe: transmedialidad, competencia y alfabetización mediática. Palabra Clave - Revista de Comunicación, v. 18, n. 3, p. 722-745, 2015.

HIDALGO-MARÍ, T.; SÁNCHEZ-OLMOS, C. Fanáticas en serie. YouTube, cultura participativa y series de televisión: estudio comparativo de género. Cuadernos.info, n. 38, p. 149-164, 2016.

HSU, L. C. et al. Investigating the ripple effect in virtual communities: An example of Facebook Fan Pages. Computers in Human Behavior, v. 51, n. PA, p. 483-494, 2015.

JENSEN, J. Fandom as Pathology: The Consequences of Characterization: London, Lewis (Ed.), 1992.

JENKINS, H. (2008). Convergence Culture. La cultura de la convergencia de los medios de comunicación. Barcelona: Paidós.

KIM, M. S.; KIM, H. M. The effect of online fan community attributes on the loyalty and cooperation of fan community members: The moderating role of connect hours. Computers in Human Behavior, v. 68, p. 232-243, 2017.

LANG, K. Reputation A2 - Wright, James D. BT - International Encyclopedia of the Social \& Behavioral Sciences (Second Edition). In: Oxford: Elsevier, 2015. p. $483-491$.

MUDRICK, M.; MILLER, M.; ATKIN, D. The influence of social media on fan reactionary behaviors. Telematics and Informatics, v. 33, n. 4, p. 896-903, 2016.

REIJNDERS, S. Stalking the count. Dracula, Fandom and Tourism. Annals of Tourism Research, v. 38, n. 1, p. 231-248, 2011.

RODRIGUEZ G., F. Medios De Comunicación Y Contracultura Juvenil. CÍRCULO de Lingüística Aplicada a la Comunicación (clac), v. 25, p. 5-30, 2006.

SANTILLÁN GARCÍA, A.; CORNEJO MARROQUÍN, C.; AUSÍN LOMAS, S. Las Fan Page de Facebook como medio de difusión de la Enfermería Basada en la Evidencia. Enfermería Global, v. 11, n. 28, p. 74-81, 2012.

SARDÁ FROUCHTMANN, J. Una historia diferente del fenómeno de los admiradores. Star, n. 94, p. 94-91, 2014.

THOMAS-JONES, A. 3 - All a twitter: celebrities and social networking BT - The Host in the Machine. In: [s.l.] Chandos Publishing, 2010. p. 33-56.

VIERA ALCAZAR, P. M. Mujeres, Tijuana y rock and roll: representaciones y autorepresentaciones de jóvenes rockeras. Debate Feminista, v. 48, p. 75-93, 2013. 